\title{
Addressing Social Determinants of Health: Community-Based Participatory Approaches to Research and Practice
}

\author{
Amy J. Schulz, PhD \\ James Krieger, MD, MPH \\ Sandro Galea, MD, MPH
}

\begin{abstract}
Medical and public health research and practice in the second half of the 20th century primarily have focused on understanding and addressing individual risk factors for diseases such as smoking, dietary practices, and blood pressure. ${ }^{1}$ Despite the tremendous resources expended on these individual risk factors, disparities between the health of those who are most advantaged and those with fewer economic and social privileges have continued and in some cases have increased. ${ }^{2-4}$ Residents of urban communities with high concentrations of poverty in particular suffer from a disproportionate burden of morbidity and mortality. ${ }^{5,6}$ Finding effective means to understand, and more important, to intervene on, the factors that contribute to racial and socioeconomic disparities in health remains one of the most pressing problems facing public health professionals today.

In this special issue of Health Education \& Behavior, we examine efforts of the Urban Research Centers (URCs), as part of the Urban Health Initiative funded by the Centers for Disease Control and Prevention, to use community-based participatory approaches to understand and develop interventions to address social determinants of health (SDOH) in three urban communities: New York City, Detroit, and Seattle. Each of these sites has engaged in community-based participatory research and interventions to address SDOH from a somewhat different perspective. This special issue offers an opportunity to examine these approaches and to highlight their potential benefits and their challenges.

In this introductory article, we first discuss a definition of social determinants and examine their role in racial and socioeconomic disparities in health, with a particular focus on urban health. Second, we discuss partnership approaches to research and practice and the particular role of such partnerships in research and interventions addressing $\mathrm{SDOH}$. We particularly examine implications of inequalities in the social context as they
\end{abstract}

Amy J. Schulz, Department of Health Behavior and Health Education, School of Public Health, University of Michigan, Ann Arbor. James Krieger, Public Health-Seattle \& King County, Seattle, Washington. Sandro Galea, Center for Urban Epidemiologic Studies, New York Academy of Medicine, New York.

Address reprint requests to Amy J. Schulz, Department of Health Behavior and Health Education, School of Public Health, University of Michigan, 1420 Washington Heights, Ann Arbor, MI 48109-2029; phone: (734) 647-0221; fax: (734) 763-7379; email: ajschulz@umich.edu.

Health Education \& Behavior, Vol. 29 (3): 287-295 (June 2002)

(C) 2002 by SOPHE 
influence health and in partnerships as they influence partnership dynamics. Third, we describe the contributions of each of the manuscripts contained within this special issue as theoretical and practical examples that illustrate the potential, and the limitations, of community-based participatory approaches to addressing SDOH. We conclude with a discussion of the implications of the ideas and results presented in these articles for the development and implementation of community-based participatory interventions at the individual, community, and policy levels.

\section{SOCIAL DETERMINANTS OF HEALTH}

The socioeconomic and racial disparities in health in the United States today require public health professionals and the communities they work with to critically examine the scope and focus of public health research and practice. Research and intervention paradigms that emphasize individual factors as risks for specific diseases have not sufficiently addressed the growing health inequalities between racial and socioeconomic groups. Different research and intervention approaches are needed to effectively understand and ameliorate these disparities. For example, despite extensive research into the causes of coronary heart disease during the past 50 years, the major known risk factors (i.e., smoking, body mass index, cholesterol, and blood pressure) explain only a portion of interindividual variability in coronary heart disease incidence. ${ }^{7,8}$ In addition, recent research suggests that these risks themselves are shaped by more distal, contextual factors such as poverty. ${ }^{9-12}$ For example, a study of low-income smokers in England ${ }^{13}$ found that smokers were more likely to live in circumstances that limited their ability to change this behavior. They had heavy day-to-day caretaking responsibilities and limited social support. Smoking emerged as a rational response for coping with a stressful environment with limited resources: It is low-cost, easily accessible, and offers a way to spend time with friends and therefore increase social support. Similarly, availability of healthy foods influences individual dietary choices, ${ }^{14-17}$ and a safe environment free from threats of violence that provides easy access to opportunities for recreation can increase physical activity. ${ }^{18,19}$ In addition, the structure and hierarchy of the workplace determine the balance between work-related demands and the ability to control these strains, which in turn influences cardiovascular health. ${ }^{20}$ Therefore, factors beyond the characteristics of the individual, directly or indirectly, play a role in determining individual risk and, ultimately, individual health. Such factors in the social environment that influence health have been termed social determinants of health and include, for example, income distribution, discrimination, access to education, and housing policies. ${ }^{21}$

Conceptual models of SDOH attempt to make explicit the connections between social and economic factors and the ways in which they shape individual risk factors, health, and well-being. ${ }^{21-25}$ They highlight relationships between what have been called fundamental determinants of health ${ }^{26}$ (e.g., the ways in which our social and economic systems are organized), more proximate factors (e.g., employment opportunities, aspects of workplace organization, exposure to infectious disease or hazards in the physical environment) and potentially protective factors (e.g., social networks and social support, access to highquality foods), with ultimate implications for individual health. Models that explicitly link different levels of risk factors contribute to our understanding of the complex relationships between socioeconomic, physical, and biological environmental factors and their influence on physiological factors and allow health practitioners to consider multi- 
ple routes of intervention. The models of social determinants that guide the work of the URCs are presented in the articles in this special issue.

Social determinants to a large extent underlie racial and socioeconomic disparities in health and well-being in the United States today. ${ }^{2,26}$ For example, neighborhoods with high poverty rates tend to have greater residential mobility; decreased commitment of residents to the community itself or to neighbors; decreased access to employment; increased stress and strain within social networks; deteriorating housing; and decreased access to supports for community life, such as municipal services, grocery stores, and banks. ${ }^{27-29}$ More advantaged residents-who have longer life expectancies - are clustered in areas that are physically distinct from those with fewer social and economic advantages and whose residents have shorter life expectancies. ${ }^{2,5,30}$ Residents of urban areas with high concentrations of poverty are more likely to be exposed to physical environmental hazards such as illegally dumped materials, airborne particulate matter, substandard housing, and contaminated soils from industrial or other waste. ${ }^{31-33}$ Furthermore, health-protective factors, such as social support ${ }^{34}$ are also inversely associated with socioeconomic status. ${ }^{2}$ Developing approaches through which to intervene effectively in the processes through which these social conditions shape health is crucial if we are to address the excess burden of morbidity and mortality currently experienced by socioeconomically disadvantaged urban residents in the United States.

\section{COMMUNITY-BASED PARTICIPATORY APPROACHES TO ADDRESSING SOCIAL DETERMINANTS OF HEALTH}

Relationships between social determinants and health are complex..$^{35} \mathrm{~A}$ full understanding of, and efforts to address, these associations will require innovative research and intervention strategies, collaboration across disciplinary groups, and engagement of community members most affected by the patterns of concentrated disadvantage. Traditional research and intervention approaches have been criticized for their failure to effectively engage such community assets as knowledge of community values, leadership, social networks, and experience in the process of designing and implementing interventions. ${ }^{17,36-41}$ Such approaches have often served to decontextualize information and failed to engage residents who were most affected in the process of understanding and developing solutions to the health and social concerns they faced. Participatory approaches arose, in part, to address these shortcomings. ${ }^{38,39,42-45}$ Community members' awareness of social processes that influence health within their communities and of ways to influence those processes are not always readily apparent to researchers and practitioners. This knowledge, however, can be critical to the success of an intervention. The complexity of the social processes that influence health requires participation by persons with a wide range of skills bringing diverse resources, influence, and knowledge to both research and intervention.

Community-based participatory partnerships are one mechanism through which to bring together such diverse individuals and organizations to affect SDOH. These approaches promote equitable engagement of residents, community-based organizations, governmental and service-providing agencies, and academic institutions in the process of designing and implementing efforts to address underlying SDOH. Communitybased participatory partnerships emphasize addressing health from positive and ecologi- 
cal perspectives, building on the strengths and resources of all parties involved, promoting learning and empowerment, equalizing power among participants, integrating knowledge and change for the mutual benefit of all partners, and ultimately disseminating findings and knowledge gained to all partners. ${ }^{39}$ A key principle of community-based participatory approaches involves identifying and building on strengths and resources within communities, allowing interventions to tap into and mobilize, for example, social networks, social support, and other important social processes that influence health.

Community-based participatory public health approaches ${ }^{38,39,46}$ have been developed in recognition of the ways that differences in social status can influence the ability of participants to work effectively together. Partnerships using these approaches recognize that social inequalities, as fundamental determinants of health, are not abstract and distant entities but are relationships that are produced and reproduced through human interactions. Thus, inequalities shape interactions between professionals and community members (e.g., in differences in access to resources or in terms of what counts as valid knowledge); between ethnic groups within a community (e.g., in disrespectful interactions between residents from different ethnic backgrounds); or within ethnic groups on the basis of, for example, gender, age, or sexual orientation. An appreciation of the pervasive impact of social inequalities on social relationships and their implications for the development of equitable and productive working relationships that draw effectively on the resources available within the community underlie the principles and process of community-based public health research and practice (for various descriptions of principles and processes for conducting community-based participatory research and practice in public health, see Hatch et al., ${ }^{38}$ Israel et al. ${ }^{39}$ Baker, ${ }^{43}$ Green et al., ${ }^{46}$ and Krieger and $\left.\mathrm{Ciske}^{47}\right)$. Such principles reflect efforts to recognize and address the pathways through which social inequalities and social hierarchies contribute to disparities: They seek to address, within the structure and the process of community-based participatory partnerships, the status differentials and social hierarchies that are fundamental to health disparities. The emphasis on participation, equity, and the integration of research and practice address the particular challenges that face residents and community-based organizations within economically marginalized communities.

Community-based participatory research and intervention models stand in contrast to the two most prevalent patterns of public health practice, that is, individual client services and population-based public health practice. Individual client services are aimed at meeting the needs of clients one by one. Population-based approaches begin with a definition of a population by public health officials, often on the basis of a disease or risk factor, and then work on that population. Although population-based public health approaches may be effective in containing the spread of an infectious agent or detecting undiagnosed disease, they may be less effective in inducing changes in individual and community practices and addressing underlying SDOH. Community-based partnerships, on the other hand, through engaging community members from project inception through its execution, build on community strengths and knowledge to identify both the key social factors that affect the health of residents in a particular community and the community resources that can be built on to most effectively address these factors.

The articles presented in this special issue reflect the efforts of the URCs to use community-based participatory approaches to integrate research and practice to understand and address SDOH. Two articles from the New York City Urban Research Center focus on understanding and addressing the social determinants of health among substance users. The article by Sandro Galea and colleagues, "Access to Resources for Sub- 
stance Users in Harlem, New York City: Service Provider and Client Perspectives" (NYC $\mathrm{CAB}$ ), presents results from surveys conducted with substance users and service providers, and the article by Stephanie H. Factor and colleagues, "Development of a 'Survival' Guide for Substance Users in Harlem, New York City" (NYC CAB), describes one effort to respond to issues identified in the surveys. Two articles from the Detroit CommunityAcademic Urban Research Center focus on a lay health adviser intervention to address SDOH. In "Addressing Social Determinants of Health Through Community-Based Participatory Research: The East Side Village Health Worker Partnership" (ESVHWP), Amy J. Schulz and colleagues describe results from a random sample community survey, in-depth interviews, and dialogue with community members about these results to establish priorities and activities for the partnership's efforts. Barbara A. Israel and colleagues present an analysis of survey data examining social support as a modifying factor in the stress-health relationship and discuss implications for practice in "The Relationship Between Social Support, Stress, and Health Among Women on Detroit's East Side." In "Using Community-Based Participatory Research to Address Social Determinants of Health: Lessons Learned From Seattle Partners for Healthy Communities" (SPHC Healthy Homes, Community Research Center [CRC], and Domestic Violence [DV] Project), James Krieger and colleagues describe lessons learned from a range of interventions undertaken by Seattle Partners for Healthy Communities to address SDOHs. Allen Cheadle and colleagues, in "Using a Participatory Approach to Provide Assistance to Community-Based Organizations: The Seattle Partners Community Research Center" (CRC), examine the development of a CRC and its role in providing support to community-based organizations as a mechanism for building stronger partnerships to address SDOH.

Together, the articles included in this special issue describe a variety of mechanisms and structures through which community members, representatives from communitybased organizations, academia, and representatives from health and social service organizations may be actively engaged in public health research and practice. Mechanisms and structures of participation include advisory groups made up of members of the intervention group (e.g., parents of children with asthma) who meet periodically to give input to project staff people and steering committee members (SPHC Healthy Homes); steering committees with responsibility for determining program objectives and overseeing implementation of the intervention (ESVHWP, SPHC Healthy Homes, SPHC DV, SPHC $\mathrm{CRC}$ ); community residents who participate in ongoing working groups to design, implement, and evaluate interventions (ESVHWP, SPHC CRC; NYC); coding of data (SPHC DV Project); interpretation of results (ESVHWP, SPHC DV, and Healthy Homes); and translation of results into interventions (ESVHWP, NYC CAB, SPHC DV, and SPHC Healthy Homes).

However, participation in and of itself is not enough. Participation may serve to reproduce inequalities, offer opportunities to challenge and disrupt inequalities, or both. ${ }^{48,49}$ Offering community members opportunities to participate in data collection but not to influence decisions about community interventions on the basis of data collected, that is, participation without influence, may simply serve to reproduce inequalities in decisionmaking processes. As partnerships assess the degree and range of opportunities for participation, they must also evaluate and critically assess the extent to which that participation offers meaningful opportunities to work in partnership, that is, to be part of the decisionmaking processes that influence not only the research questions asked but the interpretation and translation of results into interventions that address health concerns within urban 
communities. Although not the focus of this special issue, such evaluations are essential to assess the extent to which participation contributes to the objectives of equity and mutual influence that are at the core of community-based participatory approaches within public health.

\section{IMPLICATIONS FOR RESEARCH AND PRACTICE TO ADDRESS SOCIAL DETERMINANTS OF HEALTH}

As a group, these articles from the three URCs illustrate how the range of public health concerns expands when the focus is on underlying SDOH. Each site raises important questions about the scope of intervention efforts, where public health activities fit into a broader spectrum of efforts to address social inequalities, and the capacities necessary for community-based partnerships to address fundamental or underlying social conditions that contribute to health disparities.

Many of the interventions described in these articles address change at the individual or small group level, for example, by providing information about available resources to substance users, helping caretakers of children with asthma improve the quality of the indoor environment, or increasing social support among low-income women. A focus on interventions at the small group level may be viewed as a limitation when the objective is to address SDOH. On the other hand, these foci emerged from the expressed need of community residents for concrete action to address immediate health and social concerns. The literature on community organizing and mobilizing suggests the importance of specific, visible, and manageable change efforts to initiate community-building efforts. ${ }^{50-53}$ Concrete products arising from such collective efforts are an important aspect of building solidarity among members of a partnership. Interventions at the local level that have tangible and immediate benefits for local residents are an essential part of building trust and strengthening the social relationships between members of the partnership. Building strong partnerships is a first step toward building the capacity to work for macro-level change.

The projects described in this issue are beginning to address social determinants operating at the community level by mobilizing small groups of residents and community organizations and institutions to address neighborhood issues. For example, as Village Health Workers in Detroit identify diabetes as a concern in their families and communities, they note that there are no large grocery stores on Detroit's east side, limiting their access to fresh produce. Community-level interventions designed to increase the availability of fresh produce have become a priority for intervention. Similarly, a partnership formed in New York around introducing a Survival Guide for substance users and their families identifies the transition from jail back to the community as a particularly risky period for substance users. Effecting improvement in the postincarceration period for substance users requires change in local institutional policy that may guide the partnership's subsequent project. Work in Seattle identified substandard housing as an important determinant of exposure to asthma triggers. Improving housing quality for low-income households has become a priority for addressing disparities in health associated with asthma. The local asthma coalition in Seattle is beginning to work with public housing agencies to establish processes and guidelines to ensure that a family whose health is adversely affected by the condition of its housing unit is either moved to a more appropriate one or has its unit remediated. The coalition is planning a review of local health and 
housing codes to assess how well they address indoor environmental quality and how effectively they are enforced. Thus, as partnerships develop and mature, they may move from the identification of specific individual or small group concerns and strategies toward initiatives that address more macro-level causes of those concerns, that is, the underlying social and economic processes that influence social conditions-with profound implications for health.

As the role of underlying social factors in shaping health disparities becomes increasingly apparent, community-based participatory approaches to public health research and practice offer a strategy through which public health professionals and community members can work together to seek solutions. The successes and shortcomings of the URCs thus far offer useful insights for practitioners interested in engaging in community-based partnerships to address social factors that influence health in urban communities. The articles presented in this issue suggest a few central elements that underlie successful community-based partnerships.

First, each of the sites discusses a theoretical model of SDOHs that make explicit the links between social factors and health and guide the partnerships' move toward addressing social policy and broader community change. Second, the early stages of these partnerships are characterized by efforts to build trust and relationships that can become the foundation for the partnerships' actions. Third, participation must be sought not for the sake of participation but toward the end of offering meaningful opportunities to influence choice of projects, their design and implementation, and the research and evaluation questions asked. And finally, an initial focus on factors at the individual or small group level (e.g., improving information, increasing social support) may be a useful first step for partnership actions. They address immediate and salient concerns and may produce more immediate tangible results than do longer term structural and institutional change efforts, and they can serve to build relationships, trust, and mutual commitment toward the broad community-level changes suggested by theoretical models that emphasize SDOH. Eliminating health disparities will take time. Community-based partnerships focusing on the social determinants that shape these disparities can guide effective public health research and action that addresses the fundamental causes of these disparities.

\section{References}

1. Last MR: Public Health and Preventive Medicine (14th ed.), Wallace RB (ed.). Stamford, CT, Appleton \& Lange, 1998.

2. House J, Williams DR: Understanding and reducing socioeconomic and racial/ethnic disparities in health, in Institute of Medicine (ed.): Promoting Health: Intervention Strategies From Social and Behavioral Research. Washington, DC, National Academy Press, 2000, pp. 81-124.

3. McCord C, Freeman H: Excess mortality in Harlem. N Engl J Med 322:173-177, 1990.

4. Speers MA, Lancaster B: Disease prevention and health promotion in urban areas: CDC's perspective. Health Educ Behav 25(2):226-233, 1998.

5. Geronimus AT, Bound J, Waidmann TA: Poverty, time, and place: Variation in excess mortality across selected US populations, 1980-1990. J Epidemiol Community Health 53:325-334, 1999.

6. House JS, Lepkowski JM, Kinney AM, Mero RP, Kessler RC, Herzog AR: The social stratification of aging and health. J Health Soc Behav 35:213-234, 1994.

7. Rose G, Marmot BG: Social class and coronary heart disease. Br Heart J 45(1):13-19, 1981.

8. Marmot BG: Socio-economic factors in cardiovascular disease. J Hypertens 14(5):S201-S205, 1996. 
9. James SA: Primordial prevention of cardiovascular disease among African Americans: A social epidemiological perspective. Prev Med 29:S84-S89, 1999.

10. Sacker A, Bartley MJ, Frith D, Fitzpatrick RM, Marmot MG: The relationship between job strain and coronary heart disease: Evidence from an English sample of the working male population. Psychol Med 31(2):279-290, 2001.

11. Wing S, Dargent-Molina P, Casper M, Riggan W, Hayes CG, Tyroler HA: Changing association between community occupational structure and ischemic heart disease mortality in the United States. Lancet 2:1067-1070, 1987.

12. Wing S, Barnett E, Caspar M, et al: Geographic and socioeconomic variation in the onset of coronary disease mortality in white women. Am J Public Health 82:204-209, 1992.

13. Graham H: Gender and class as dimensions of smoking behaviour in Britain: Insights from a survey of mothers. Soc Sci Med 38(5):691-698, 1994.

14. Cheadle A, Psaty BM, Curry S, Wagner E, Diehr P, Koepsell T, Krsital A: Community-level comparisons between the grocery store environment and individual dietary practices. Prev Med 20:250-261, 1991.

15. Nestle M, Jacobson MF: Halting the obesity epidemic: A public health policy approach. Public Health Rep 115(1):12-24, 2000.

16. Swinburn B, Egger G, Raza F: Dissecting obesogenic environments: The development and application of a framework for identifying and prioritizing environmental interventions for obesity. Prev Med 29:563-570, 1999.

17. Travers KD: The social organization of nutritional inequities. Soc Sci Med 43(4):543-553, 1996.

18. Sherwood NE, Jeffery RW: The behavioral determinants of exercise: Implications for physical activity interventions. Annu Rev Nutr 20:21-44, 2000.

19. Stahl, T, Rutten A, Nutbeam D, Bauman A, Kannas L, Abel T, Luschen G, Diaz-Rodriquez JA, Vinck J, van der Zee J: The importance of the social environment for physically active lifestyle-Results from an international study. Soc Sci Med 52(1):1-10, 2001.

20. Theorell T, Alfredsson L, Westerholm P, Falck B: Coping with unfair treatment at work-What is the relationship between coping and hypertension in middle-aged men and women? An epidemiological study of working men and women in Stockholm (the WOLF study). Psychother Psychosom 69(2):86-94, 2000.

21. Marmot M: Introduction, in Marmot M, Wilkinson RG (eds.): Social Determinants of Health. New York, Oxford University Press, 1999, pp. 17-43.

22. Baum A, Garofalo JP, Yali AM: Socioeconomic status and chronic stress: Does stress account for SES effects on health? Ann N Y Acad Sci 896:1131-1144, 1999.

23. Evans RG, Stoddart GL: Producing health, consuming health care. Soc Sci Med 31(12):1347$1363,1990$.

24. Kaplan G. What is the role of the social environment in understanding inequalities in health? Ann N Y Acad Sci , 896:116-119, 1999.

25. Navarro V, Shi L: The political context of social inequalities and health. Soc Sci Med 52(3):481$491,2001$.

26. Link BG, Phelan J: Social conditions as fundamental causes of disease (Extra issue). J Health Soc Behav 36:80-94, 1995.

27. Dunn JR, Hayes MV: Social inequality, population health and housing: A study of two Vancouver neighborhoods. Soc Sci Med 51:563-587, 2000.

28. Ellen IG, Turner MA: Does neighborhood matter? Assessing recent evidence. Housing Policy Debate 8(4):833-866, 1997.

29. Saegert S, Winkel G: Social capital and the revitalization of New York City's distressed innercity housing. Housing Policy Debate 9(1):17-60, 1998.

30. Williams DR, Collins C: US socioeconomic and racial differences in health: Patterns and explanations. Annu Rev Sociol 21:349-386, 1995.

31. Bullard R. (ed.): Unequal Protection: Environmental Justice and Communities of Color. San Francisco, Sierra Club Books, 1994. 
32. Bryant B, Mohai P: Race and the Incidence of Environmental Hazards: A Time for Discourse. Boulder, CO, Westview, 1992.

33. Freudenberg $\mathrm{N}$ : Community-based health education for urban populations: An overview. Health Educ Behav 25(1):11-23, 1998.

34. Berkman LF, Leo-Summers L, Horwitz RI: Emotional support and survival after myocardial infarction. A prospective, population-based study of the elderly. Ann Intern Med 117(12):10031009, 1992.

35. Philippe P, Mansi O: Nonlinearity in the epidemiology of complex health and disease processes. Theor Med Bioeth 19(6):591-607, 1998.

36. Gaventa J: The powerful, the powerless, and the experts: Knowledge struggles in an information age, in Park P, Brydon-Miller M, Hall B, Jackson T (eds.): Voices of Change: Participatory Research in the United States and Canada. Westport, CT, Bergin \& Harvey, 1993, pp. 21-40.

37. Hall B: From margins to center? The development and purpose of participatory research. Am Sociol 23(4):15-28, 1992.

38. Hatch J, Moss N, Saran A, Presley-Cantrell L, Mallory C: Community research: Partnership in Black communities. Am J Prev Med 9(6):27-31, 1993.

39. Israel BA, Schulz AJ, Parker EA, Becker AB: Review of community-based research: Assessing partnership approaches to improve public health. Annu Rev Public Health 19:173-202, 1998.

40. Maguire P. Considering more feminist participatory research: What's congruency got to do with it. Qualitative Inquiry 2:106-118, 1996.

41. Wallerstein N: Power between evaluator and community: Research relationships within New Mexico's healthier communities. Soc Sci Med 49:39-53, 1999.

42. Baker EA, Brownson CA: Defining characteristics of community-based health promotion programs. J Public Health Management Practice 4(2):1-9, 1998.

43. Baker EA, Homan S, Schonhoff R, Kreuter MW: Principles of practice for academic/practice/ community research partnerships. Am J Prev Med 16(3):86-93, 1999.

44. Steuart G: The people: Motivation, education and action. Bulletin Academy of Medicine 51:174-185, 1975 .

45. Stoeker R, Beckwith D: Advancing Toledo's neighborhood movement through participatory action research: Integrating activist and academic approaches. Clin Sociol Rev 10:198-213, 1992.

46. Green LW, George MA, Daniel M, Frankish CJ, Herbert CJ, et al: Study of participatory research in health promotion. Vancouver: University of British Columbia, Royal Society of Canada, 1995.

47. Krieger J, Ciske S: The community as partner in public health initiatives. Washington Public Health 17:47-50, 2000.

48. Arnstein S: The ladder of citizen participation. J Am Institute Planners 35:216-224, 1969.

49. Willis P: Learning to Labor: How Working Class Kids Get Working Class Jobs. New York, Columbia University Press, 1977.

50. Alinsky S: Rules for radicals. New York, Vintage, 1971.

51. Blaine TM, Forster JL, Hennrikus D, O’Neil S, Wolfson M, Pham H: Creating tobacco control policy at the local level: Implementation of a direct action organizing approach. Health Educ Behav 24(5):640-651, 1997.

52. Minkler M, Wallerstein $\mathrm{N}$ : Improving health through community organization and community building, in Glanz K, Lewis FM, Rimer BK (eds.): Health Behavior and Health Education: Theory, Reseach, and Practice. San Francisco, Jossey-Bass, 1997, pp. 241-269.

53. Person B, Cotton D: A model of community mobilization for the prevention of HIV in women and infants. Prevention of HIV in Women and Infants Demonstration Projects. Public Health Rep 111(suppl. 1):89-98, 1996. 